\title{
3 \\ Overview of Biological, \\ Chemical, and Physical Hazards
}

\author{
E. Jeffery Rhodehamel
}

\section{INTRODUCTION}

HACCP is a systematic approach to be used in food production as a means to ensure food safety. The first step requires a hazard analysis, an assessment of risks associated with all aspects of food production from growing to consumption. However, before one can assess the risks, a working knowledge of potential hazards must be obtained. A hazard is defined by the National Advisory Committee on Microbiological Criteria for Foods (NACMCF) as any biological, chemical, or physical property that may cause an unacceptable consumer health risk. Thus, by definition one must be concerned with three classes of hazards; biological, chemical, and physical.

This chapter provides a generalized background of the potential hazards associated with foods. Appropriate reference materials on food hazards have been included. A number of textbooks are available on the subject of hazards in foods.

\section{BIOLOGICAL HAZARDS}

The first hazard category, biological or microbiological, can be further divided into three types: bacterial, viral, and parasitic (protozoa and worms). Many HACCP programs are designed specifically around the microbiological hazards. Archer and Kvenberg (1985) and Todd (1989) estimated that the incidence of foodborne illness ranges from 12.6 to 81 million cases per year with a cost of 1.9 to 8.4 billion dollars. HACCP programs address this food safety problem by assisting in the production of safe wholesome foods. Excellent references exist on biological hazards (Cliver 1990), foodborne pathogenic bacteria (Doyle 
1989; Riemann and Bryan 1979), viruses (Cliver 1988), and parasitic protozoa and worms (Healy et al. 1984; Jackson 1990).

Table 3-1 lists hazardous bacteria, viruses, and parasitic protozoa and worms, which include the microorganisms of concern in HACCP programs. The International Commission of Microbiological Specifications for Food (ICMSF 1986) attempted to group some of these hazardous microorganisms according to severity of risk (Table 1). The pathogens in Group I present a severe hazard; those in

TABLE 3-1 Hazardous Microorganisms and Parasites Grouped on the Basis of Risk Severity ${ }^{a}$

I. Severe Hazards

Clostridium botulinum types A, B, E, and F

Shigella dysenteriae

Salmonella typhi; paratyphi A, B

Hepatitis A and E

Brucella abortis; $B$. suis

Vibrio cholerae $\mathrm{O} 1$

Vibrio vulnificus

Taenia solium

Trichinella spiralis

II. Moderate Hazards: Potentially Extensive Spread ${ }^{b}$

Listeria monocytogenes

Salmonella spp.

Shigella spp.

Enterovirulent Escherichia coli (EEC)

Streptococcus pyogenes

Rotavirus

Norwalk virus group

Entamoeba histolytica

Diphyllobothrium latum

Ascaris lumbricoides

Cryptosporidium parvum

III. Moderate Hazards: Limited Spread

Bacillus cereus

Campylobacter jejuni

Clostridium perfringens

Staphylococcus aureus

Vibrio cholerae, non-O1

Vibrio parahaemolyticus

Yersinia enterocolitica

Giardia lamblia

Taenia saginata

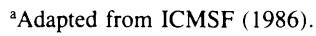

${ }^{b}$ Although classified as moderate hazards, complications and sequelae may be severe in certain susceptible populations. 
Group II are considered moderate hazards (although the illnesses in certain susceptible populations or complications can be severe) with the potential for extensive spread of the disease. Pathogens in Group III cause common-source outbreaks; however, subsequent spread is either rare or limited.

When developing a HACCP program, the food grower or processor should have three basic aims with regard to biological hazards: (1) destroy, eliminate, or reduce the hazard; (2) prevent recontamination; and (3) inhibit growth and toxin production. Preventive measures should be taken to achieve these goals.

Microorganisms can be destroyed or eliminated by thermal processing, freezing, and drying. After the microorganism has been eliminated, measures to prevent recontamination should be taken. Finally, if the hazard cannot be totally eliminated from the food, microbial growth and toxin production must be inhibited. Growth can be inhibited through the intrinsic characteristics of the food, such as $\mathrm{pH}$ and water activity $\left(\mathrm{a}_{\mathrm{w}}\right)$, or by the addition of salt or other preservatives. Conditions under which the food is packaged (aerobic or anaerobic) and storage temperatures (refrigeration or freezing) can also be used to inhibit growth.

\section{Bacterial hazards}

Bacterial hazards can result either in foodborne infections or intoxications. A foodborne infection is caused by ingesting a number of pathogenic microorganisms sufficient to cause infection, and the reaction of tissues to their presence, multiplication, or elaboration of toxins. A foodborne intoxication is caused by the ingestion of preformed toxins produced and excreted by certain bacteria when they multiply in foods (Bryan 1979).

Table 3-2 lists the source, disease characteristics, and food associated with various foodborne bacterial pathogens. Although not all-inclusive, the list represents the pathogens that are reported to cause foodborne disease outbreaks and that are responsible for numerous cases of illness. Many food commodities have a unique microbiology and group of associated pathogens. Processors of specific foods (e.g., seafood) should consult reference materials in those areas (e.g., Ward and Hackney 1991).

The following summary discusses the notable characteristics of the various foodborne bacterial pathogens of concern to the food industry and their relationship to the development of a HACCP program. The natural incidence and the severity of disease caused by these bacteria, along with the general conditions required for their control represent a cross-section of challenges for HACCP programs. If these organisms are controlled, numerous other pathogens may be similarly controlled.

Clostridium botulinum. Clostridium botulinum, the causative agent of botulism (foodborne intoxication), is an anaerobic, sporeforming rod that produces a potent 


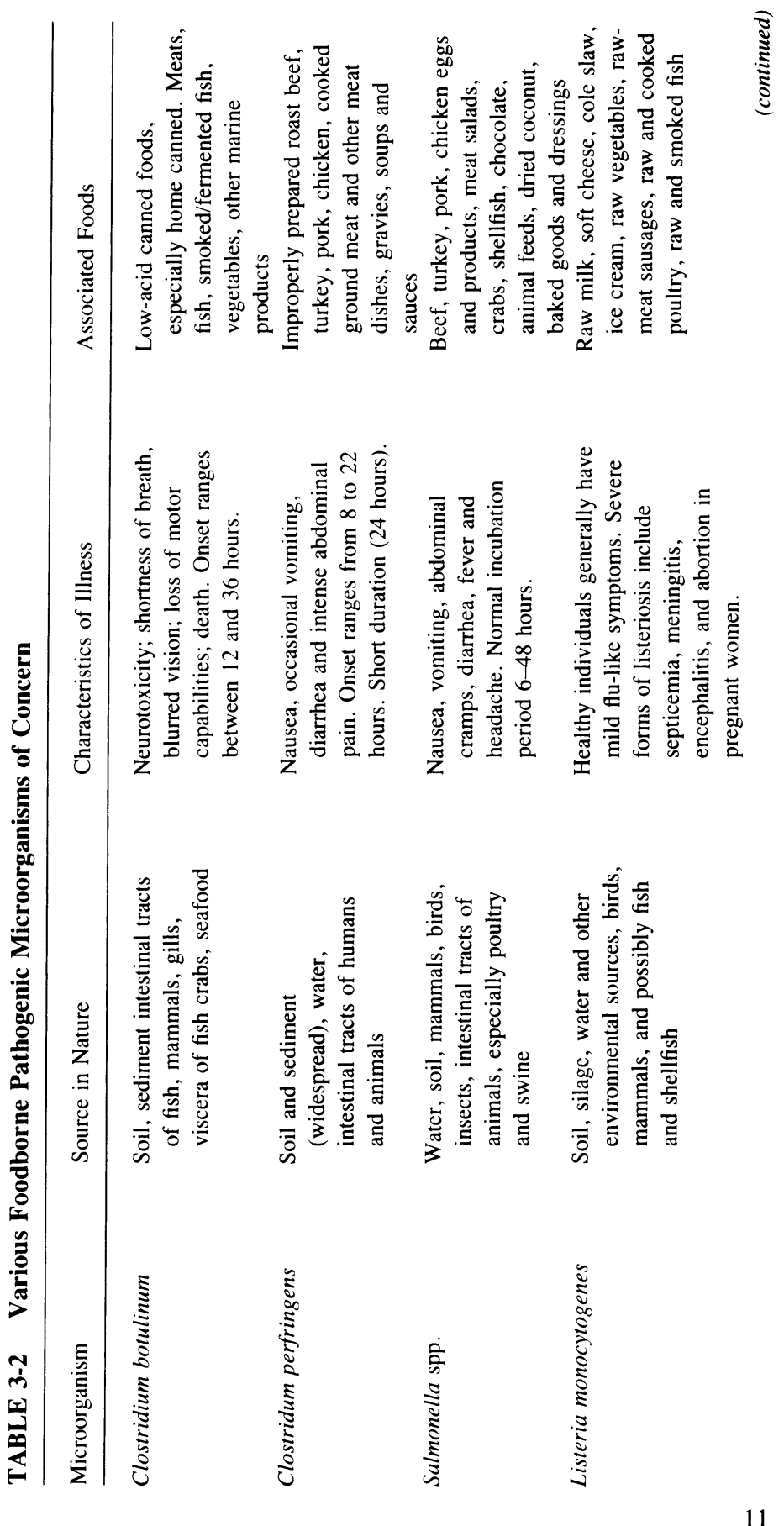




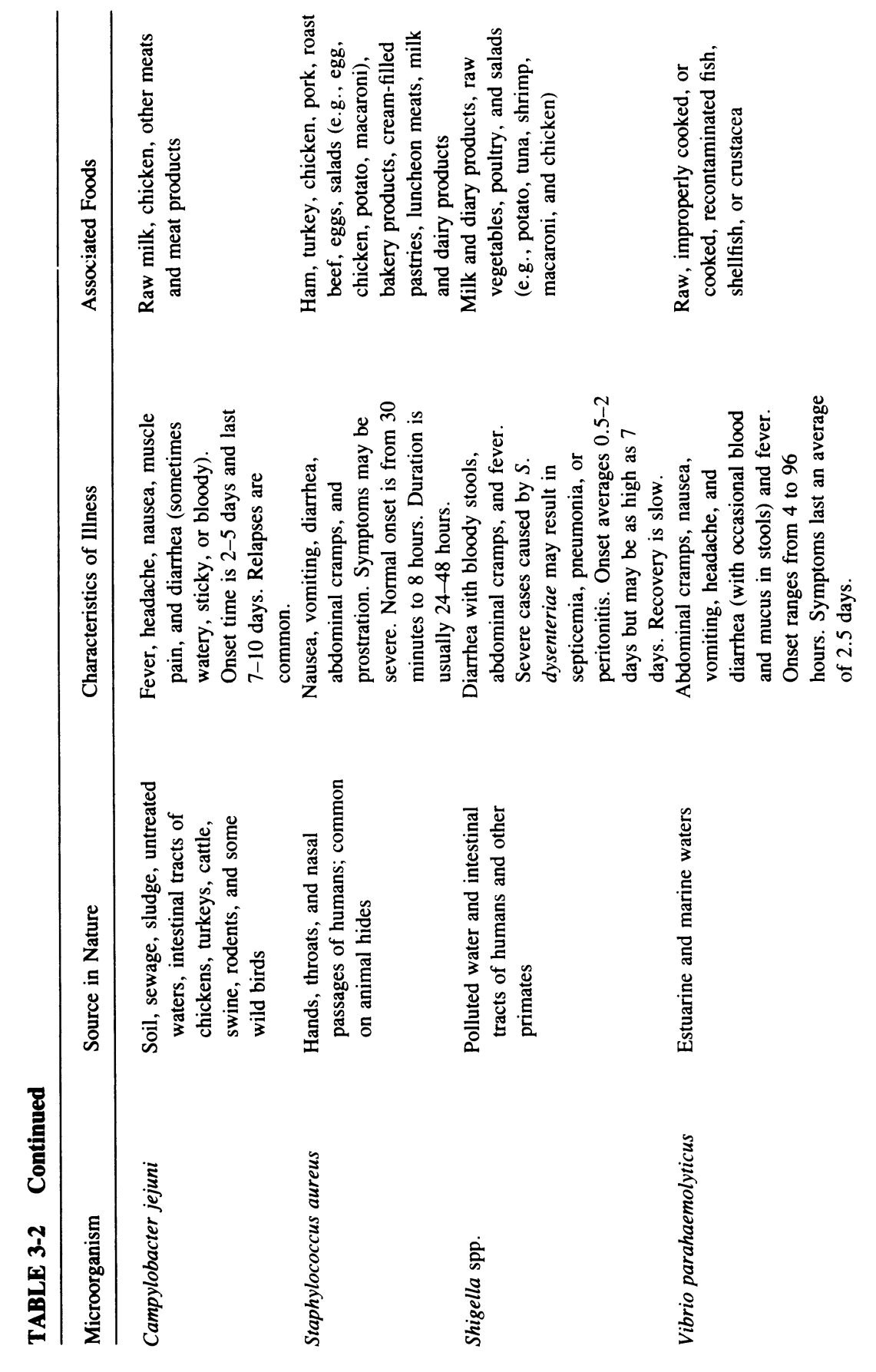



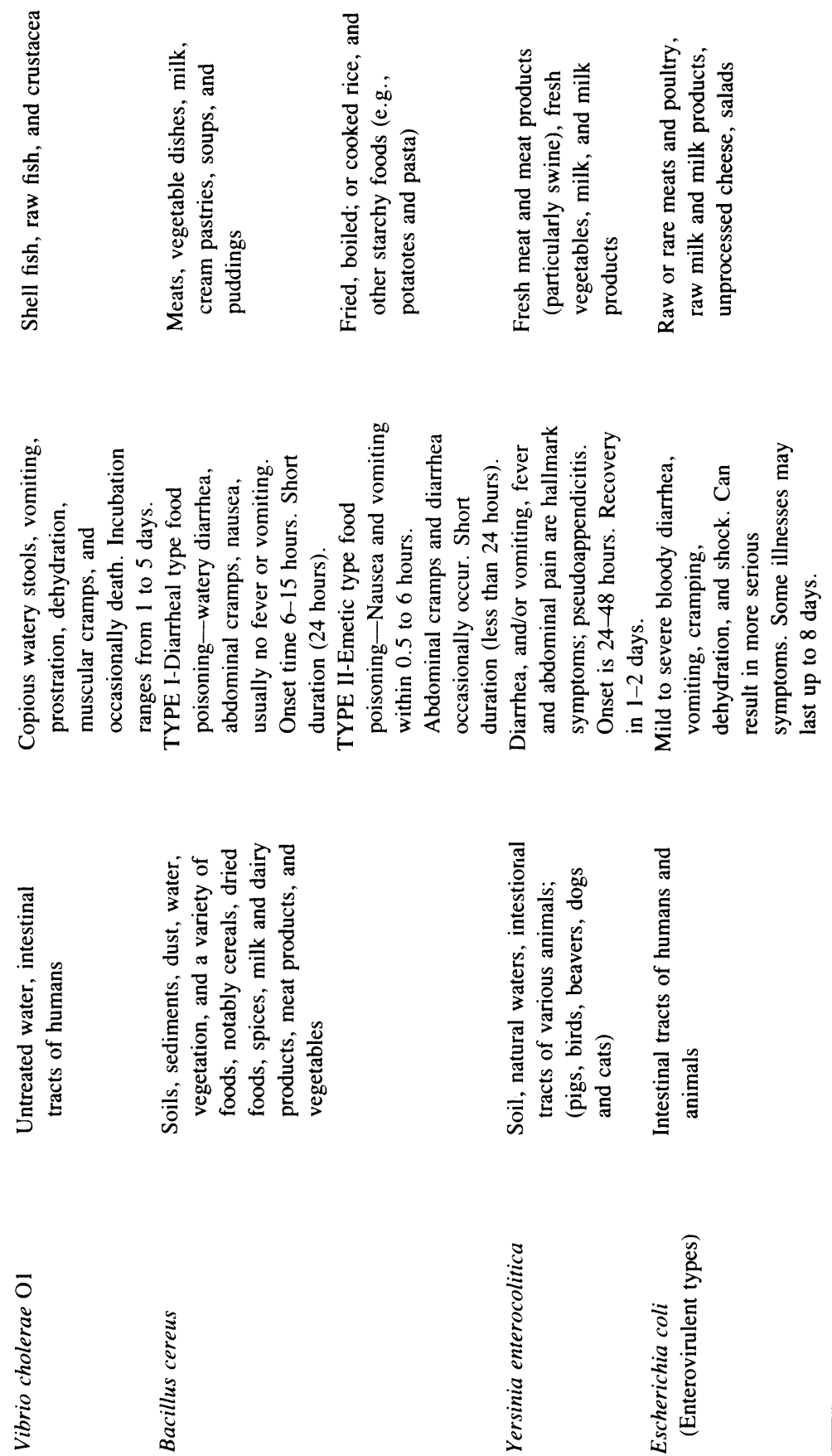
neurotoxin. Its notable characteristics are its heat-resistant spores and their widespread distribution. Some strains of $C$. botulinum are psychotrophic. The spores survive most thermal processes except those specifically designed to eliminate them (e.g., 12D thermal processing of low-acid canned foods). If such a process is not used, one must assume that spores are present in the food. If the food is to be packaged in an anaerobic or reduced oxygen atmosphere, measures to inhibit the growth and toxin production by the organism are necessary. C. botulinum growth can be controlled by one or a combination of the following conditions: $\mathrm{pH}<4.6 ; \mathrm{a}_{\mathrm{w}} \leqslant 0.94 ; 5-10 \%$ salt concentration; nitrite and salt combinations (e.g., cured meats); other preservatives; temperature control (freezing/refrigeration), and biocontrol (e.g., inoculation of product with lactic acid bacteria). Sole reliance on refrigeration to ensure safety is risky. Botulinum toxin produced is one of the most potent substances known but is relatively heat labile (destroyed by boiling for 10 minutes). Reliance on final cooking by the consumer to destroy the toxin is extremely risky.

Listeria monocytogenes. Listeria monocytogenes is a hazardous foodborne microorganism of relatively recent concern. It is ubiquitious in nature and is commonly found in food processing environments. It causes listerosis, a severe and often fatal illness, to which certain populations (e.g., pregnant mothers, newborns, immunocomprised individuals, transplant recipients) may be susceptible. Fatality rates with the more severe forms of listeriosis can be as high as $70 \%$ for those untreated, but generally are between 25 and $35 \%$. The organism is psychotrophic and can grow at refrigeration temperatures. Its widespread distribution and its ability to multiply at refrigeration temperatures and cause severe illness make it a hazard of particular concern to the food industry and regulatory agencies. HACCP programs should attempt to destroy, eliminate, or reduce this hazard and prevent the opportunity for subsequent recontamination.

Salmonella. Salmonella species can be found on most raw foods of animal origin. Salmonellosis is one of the most frequently reported foodborne diseases. Symptoms of salmonellosis are most severe in susceptible populations (the elderly, infants, and the infirm). Although about 40,000 cases are reported each year, it is estimated that 2-4 million cases occur annually. Salmonella species are destroyed by normal pasteurization processes and are most commonly spread through contamination of processed materials with raw products or with the juices of raw products via hands, utensils, or food-contact surfaces. HACCP plans for processed foods should include controls to destroy and eliminate this organism and to prevent recontamination.

Staphylococcus aureus. Staphylococcus aureus may produce a very heat-stable enterotoxin when permitted to grow to an elevated level $\left(>10^{5}\right.$ organisms/g). The foodborne intoxication is caused by ingesting enterotoxins produced in food 
by some strains of $S$. aureus, usually because the food has not been kept hot enough $\left(>60^{\circ} \mathrm{C} ; 140^{\circ} \mathrm{F}\right)$ or cold enough $\left(\leqslant 7.2^{\circ} \mathrm{C} ; 45^{\circ} \mathrm{F}\right.$ or below $)$. The organism is commonly isolated from hands and nasal passages of humans. Thus, foods which are handled or require preparation are at risk. The organism can grow at an $\mathrm{a}_{\mathrm{w}}$ of 0.86 and in high salt concentrations. Proper preprocessing handling of raw materials is essential. If conditions allow the organism to grow and produce enterotoxins, subsequent thermal processing will destroy the vegetative organisms while the head-stable toxin persists. There is evidence that the enterotoxins may not be completely inactivated at retort temperatures $\left(121^{\circ} \mathrm{C}\right.$ or $\left.250^{\circ} \mathrm{F}\right)$. HACCP plans should provide for proper handling of raw materials, steps to destroy, eliminate, or reduce the hazard and controls to prevent recontamination. If organisms can reasonably be expected in the final product, conditions to inhibit growth and toxin production should be controlled.

Clostridium perfringens. Clostridium perfringens is another anaerobic, sporeforming, rod-shaped bacterium. Perfringens food poisoning is caused by consuming foods that contain large numbers of those $C$. perfringens strains that are capable of producing the food poisoning toxin, which is usually formed in the digestive tract and is associated with sporulation. Limited evidence exists that preformed toxin can be found in food. Perfringens food poisoning is frequently associated with food service operations; temperature abuse of prepared foods, such as large poultry or cooked cuts of meat and gravies and sauces prepared in large containers, can provide anaerobic conditions. Because spores are heat resistant, small numbers of organisms may be present after cooking (or large numbers after improper cooking). Subsequent temperature abuse [not keeping cooked foods above $60^{\circ} \mathrm{C}\left(140^{\circ} \mathrm{F}\right)$ or not providing rapid, even cooling to refrigeration temperatures] may permit the organisms to multiply to food poisoning levels. HACCP plans should control proper cooking conditions and subsequent handling temperatures to inhibit growth of this organism.

Information on the specific limiting growth parameters, heat resistance, growth inhibitors or particular resistance to chemical disinfectants for these and other foodborne bacterial pathogens is available in reference textbooks (Cliver 1990; Doyle 1989; Shapton and Shapton 1991).

\section{Viral hazards}

Viruses are very small particles that cannot be seen with a light microscope. They are obligate intracellular parasites that are unable to reproduce outside the host cell. Thus, they are inert in foods and do not multiply in them (Cliver 1988). However, viruses may be transmitted to foods via the fecal-oral route, either directly or indirectly. Some viruses may be inactivated in foods by thorough cooking and some by drying. However, contamination of foods with viruses should be avoided. Direct contamination can occur when an infected food handler 
contaminates food. Indirect contamination can occur when foods such as bivalve mollusks become contaminated in waters infected by untreated sewage. The viruses most commonly recognized as foodborne disease agents are summarized below.

Hepatitis A virus. Hepatitis A virus (HAV) is classified with the enterovirus group of the Picornaviridae family. The terms hepatitis A or type A viral hepatitis have replaced all previous names for the illness. Hepatitis A is usually a mild illness characterized by sudden onset of fever, malaise, nausea, anorexia, and abdominal discomfort, followed in several days by jaundice. Occasionally, the symptoms are severe and convalescence can take several months. The incubation period for hepatitis A varies from 10 to 50 days (mean 30 days). The period of virus shedding or communicability extends from early in the incubation period to about a week after the development of jaundice. The greatest danger of spreading the disease to others occurs 10-14 days before the first presentation of symptoms. The infectious dose is unknown but presumably is $10-100$ virus particles.

HAV is excreted in feces of infected individuals and contaminates water or foods via the fecal-oral route. Virtually any food that is handled by an infected worker and not further cooked can serve as a vehicle for transmission. Shellfish (bivalue mollusks), salads, cold cuts and sandwiches, fruits and fruit juices, milk and milk products, vegetables, and iced drinks are commonly implicated in outbreaks. Shellfish (bivalue mollusks), and salads are the most frequent food sources. Virus transmission through foods can best be avoided by preventing fecal contamination and thoroughly cooking foods before consumption.

The Norwalk virus family. Norwalk virus is the prototype of a family of unclassified small round structured viruses (SRSVs) which may be related to the caliciviruses. Common names of the illness caused by the Norwalk and Norwalklike viruses are viral gastroenteritis and acute nonbacterial gastroenteritis. The disease is self-limiting, mild, and characterized by nausea, vomiting, diarrhea, and abdominal pain. Headache and low-grade fever may occur. The infectious dose is unknown but presumed to be low. Norwalk gastroenteritis is transmitted by the fecal-oral route via contaminated water and foods. Secondary person-toperson transmission has also been documented. Water is the most common source of outbreaks and may include water from municipal supplies, well, recreational lakes, swimming pools, and water stored aboard cruise ships. Salad ingredients and shellfish are the foods most often implicated in Norwalk outbreaks. Ingestion of raw or insufficiently steamed clams and oysters poses a high risk for infection with Norwalk virus. A variety of foods other than shellfish are contaminated by ill food handlers and include salads, fruits, eggs, clams, and bakery items. 
Rotavirus. Rotaviruses are classified with the Reoviridae family. Rotaviruses cause acute gastroenteritis. Infantile diarrhea, winter diarrhea, acute nonbacterial infectious gastroenteritis, and acute viral gastroenteritis are names applied to the infection caused by the most common and widespread group A rotavirus. Rotavirus gastroenteritis is a self-limiting, mild-to-severe disease characterized by vomiting, watery diarrhea, and low-grade fever. The infective dose is presumed to be 10-100 infectious viral particles. Rotaviruses are transmitted by the fecaloral route. Infected food handlers may contaminate foods that require handling and no further cooking, such as salads, fruits, and hors d'oeuvres. The virus has not been isolated from any food associated with an outbreak, and no satisfactory method is available for routine analysis of food. Control measures to prevent rotavirus transmission in foods are similar to those used for other viral agents.

Other viruses associated with gastroenteritis. Although the rotavirus and the Norwalk family of viruses are the leading causes of viral gastroenteritis, a number of other viruses have been implicated in outbreaks, including astroviruses, caliciviruses, enteric adenoviruses, and parvovirus. Astroviruses, caliciviruses, and the Norwalk family of viruses possess well-defined surface structures and are sometimes identified as "small round structured viruses" or SRSVs. Viruses with a smooth edge and no discernible surface structure are designated "featureless viruses" or "small round viruses" (SRVs). These agents resemble enterovirus or parvovirus, and may be related to them.

Common names of the illness caused by these viruses are acute nonbacterial infectious gastroenteritis and viral gastroenteritis. Viral gastroenteritis is usually a mild illness characterized by nausea, vomiting, diarrhea, malaise, abdominal pain, headache, and fever. The clinical features are milder but otherwise indistinguishable from rotavirus gastroenteritis. Co-infections with other enteric agents may result in more severe illness lasting a longer period of time. The infectious dose is unknown but is presumed to be low. Viral gastroenteritis is transmitted by the fecal-oral route via person-to-person contact or ingestion of contaminated foods and water. Infected food handlers may contaminate foods that are not further cooked before consumption. Enteric adenovirus may also be transmitted by the respiratory route. Shellfish have been implicated in illness caused by a parvo-like virus.

\section{Parasitic protozoa and worm hazards}

Parasites are organisms that derive their sustenance on or within their host. A variety of parasitic animals are of concern to the food microbiologist. They include protozoa, nematodes (roundworms), cestodes (tapeworms), and trematodes (flukes). Table 3-3 lists the parasitic protozoa and worms that are relevant 

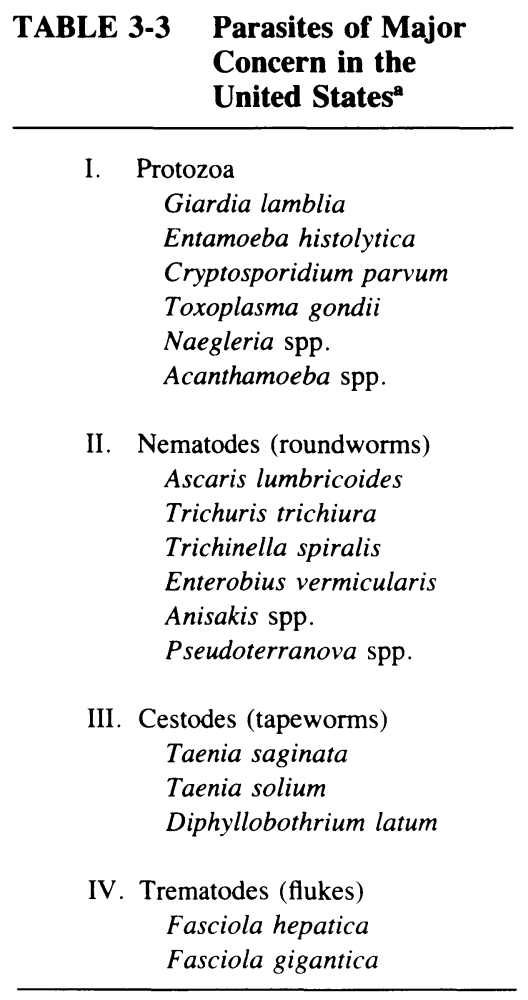

a(Jackson 1990).

to the food industry in the United States (Jackson 1990). Some foodborne parasites may be transmitted through food and water contaminated by fecal material that contains parasites shed by infected hosts. Other parasites spend a portion of their life cycle in food animals and are thus ingested along with the food. Methods for preventing transmission of parasites to foods via the fecal contamination route include good personal hygiene practices by food handlers, proper disposal of human feces, eliminating the use of insufficiently treated sewage to fertilize crops, and proper sewage treatment. Thorough cooking of foods will eliminate all foodborne parasites. Freezing, and in specific instances brining, may be used to destroy various parasites in foods.

The following overview discusses selected parasitic protozoa and worms. Additional information may be found in these references: Cheng 1986; Cliver 1990; Healy et al. 1984; Jackson 1990. 
Giardia lamblia. Giardia lamblia (intestinalis) is a single-celled protozoa that causes giardiasis in humans. G. lamblia exists in two separate stages: the active feeding (trophozoite) stage and the infective environmental (cyst) stage in which the organism survives outside the host. Human giardiasis may involve diarrhea within a week after the cyst is ingested. Other symptoms include abdominal cramps, fatigue, nausea, flatulence, and weight loss. The illness may last for one to two weeks, but chronic infections may last months to years. Colonization and pathogenesis generally occur in the lumen of the small intestine, but the disease mechanism is unknown. G. lamblia is shed in the feces of infected individuals and is transmitted via the fecal-oral route. Giardiasis is most frequently associated with the consumption of contaminated water. Outbreaks have been traced to food contamination by infected food handlers, and the possibility of infection from contaminated vegetables that are eaten raw cannot be excluded. Cool moist conditions favor the survival of the organism. Food contamination by infected food workers can be prevented by proper personal hygiene. Thorough cooking of foods destroys $G$. lamblia.

Entamoeba histolytica. Entamoeba histolytica is a single-celled protozoa that predominantly infects humans and other primates. Like $G$. lamblia, E. histolytica can exist as two separate stages: a trophozoite or a cyst. Cysts survive outside in water, in soils, and on foods, especially under moist conditions. When swallowed, they cause infections by excysting (to the trophozoite stage) in the digestive tract. Infections can be asymptomatic or accompanied by a mild gastrointestinal distress or dysentery (with blood and mucus). E. histolytica may penetrate the intestinal wall, and if it enters the blood, may gain access to other organs. Large numbers of cysts can be shed in the feces of infected individuals. $E$. histolytica is transmitted via the fecal-oral route. Infection can result from the fecal contamination of drinking water and foods, and by direct contact with dirty hands or objects. Preventive measures are similar to those described for $G$. lamblia.

Ascaris lumbricoides. Humans worldwide are infected with Ascaris lumbricoides. The eggs of this roundworm (nematode) are "sticky" and may be carried to the mouths by hands, other body parts, fomites (inanimate objects), or foods. Ascariasis, the scientific name for this infection, is also commonly known as the "large roundworm" infection. Ingested eggs hatch in the intestine, and larvae begin to migrate, reaching the lungs through the blood and lymph systems. In the lungs, the larvae break out of the pulmonary capillaries into the air sacs, ascend into the throat, and descend again to the small intestine where they grow to sexual maturity. On occasion, larvae will crawl up into the throat and try to exit through the mouth or nose. Vague digestive tract discomfort sometimes 
accompanies the intestinal infection, but intestinal blockage may occur in small children who have more than a few worms because of the large size of the worms. Large numbers of eggs may be voided in feces. A. lumbricoides eggs are extremely resistant to sewage treatment and may survive in soil for years. The eggs are found in insufficiently treated sewage fertilizer and in soils where they embryonate (i.e., larvae develop in fertilized eggs). The eggs may contaminate crops grown in soil or fertilized with sewage that has received nonlethal treatment. Humans are infected when such produce is consumed raw. Infected foodhandlers may contaminate a wide variety of foods. Careful disposal of human feces and avoiding fertilization of crops with insufficiently treated sewage are key preventive measures. Eggs are slightly susceptible to drying and begin losing their infectivity at temperatures above $38^{\circ} \mathrm{C}$ (Cliver 1990).

Diphyllobothrium latum. Diphyllobothrium latum and other members of the genus are broad fish tapeworms (cestodes). D. latum is a broad, long tapeworm, often growing to lengths between 1 and 2 meters (3-7 feet) and potentially capable of attaining 10 meters ( 32 feet). The disease caused by broad fish tapeworm infections is called diphyllobothriasis. Infections are acquired by consumption of raw, underprocessed or lightly cooked fish. Freshwater fish (e.g., pike, burbot, and perch) and those that migrate between ocean and fresh waters (salmonid fishes) may be infected. The larvae that infect people (plerocercoid) are frequently encountered in the viscera of freshwater and marine fishes. The ingested plerocercoid develops into a mature adult tapeworm and attaches itself to the intestinal wall. Diphyllobothriasis is characterized by abdominal distention, flatulence, intermittent abdominal cramping, and diarrhea with onset about 10 days after consumption of raw or insufficiently cooked fish. The tapeworm has a strong affinity for vitamin $B_{12}$ and may cause a deficiency in the host. In regions where raw or lightly cooked fish are eaten, the frequency of the disease tends to be high. Preventive measures call for adequate cooking of fish foods. Other methods proposed for destroying the larvae in infected fish include freezing or brining at high salt concentrations.

\section{CHEMICAL HAZARDS}

Webster defines a chemical as any substance used in or obtained by a chemical process or processes. All food products are made up of chemicals, and all chemicals can be toxic at some dosage level. However, a number of chemicals are not allowed in food and others have established allowable limits. A summary of most of the chemical hazards in foods has been compiled (Bryan 1984). The two types of chemical hazards in foods are naturally occurring and added chemicals (Table 3-4). Both may potentially cause chemical intoxications if excessive levels are present in a food. For additional information, see Chemical Intoxi- 


\section{TABLE 3-4 Types of Chemical Hazards}

I. Naturally occuring chemicals

Mycotoxins (e.g., aflatoxin)

Scombrotoxin (histamine)

Ciguatoxin

Mushroom toxins

Shellfish toxins

Paralytic shellfish poisoning (PSP)

Diarrheic shellfish poisoning (DSP)

Neurotoxic shellfish poisoning (NSP)

Amnesic shellfish poisoning (ASP)

Pyrrolizidine alkaloids

Phytohemagglutinin

Polychlorinated biphenyls (PCBs)

II. Added chemicals

Agricultural chemical

Pesticides, fungicides, fertilizers, insecticides, antibiotics and growth hormones

Prohibited substances (21 CFR, Section 189)

Direct

Indirect

Toxin elements and compounds

Lead, zinc, arsenic, mercury and cyanide

Food additives

Direct-allowable limits under GMPs

Preservatives (nitrite and sulfiting agents)

Flavor enhancers (monosodium glutamate)

Nutritional additives (niacin)

Color additives

Secondary direct and indirect

Plant chemicals (e.g., lubricants, cleaners,

sanitizers, cleaning compounds, coating

and paint)

Chemicals intentionally added (sabotage)

cations and Naturally Occurring Toxicants in Foods in Foodborne Diseases (Cliver 1990). Many HACCP programs have been criticized for their relative neglect of chemical and physical hazards.

\section{Naturally occurring chemicals}

If formal limits have been established for naturally occurring toxicants, the limit will be found in the Code of Federal Regulations, Title 21. If informal limits have been established (e.g., aflatoxins, paralytic shellfish toxin, and scombrotoxin), the maximum allowable limit will be found in the Food and Drug Admin- 
istration's (FDA) Compliance Policy Guidelines, available from FDA, Center for Food Safety and Applied Nutrition HFF-300, Washington, DC 20204. The naturally occurring toxicants include a variety of chemicals of plant, animal, or microbial origin. Although many naturally occurring toxicants are biological in origin, they have traditionally been categorized as chemical hazards. However, for individual HACCP programs, their inclusion in the biological hazard category would be equally appropriate. The following overview discusses several naturally occurring toxicants.

Mycotoxins. A number of fungi produce compounds (mycotoxins) toxic to man (Stoloff 1984). Mycotoxins are secondary metabolites of certain fungi. Among some of the better known and studied groups of mycotoxins are the aflatoxins, which include a group of structurally related toxic compounds produced by certain strains of the fungi Aspergillus flavus and A. parasiticus. Under favorable conditions of temperature and humidity, these fungi grow and produce aflatoxins on certain foods, grains, nuts, and feeds. The most pronounced contamination has been encountered in tree nuts, peanuts, and other oilseeds including corn and cottonseed. The major aflatoxins of concern are designated $B_{1}, B_{2}, G_{1}$, and $G_{2}$, which are usually found together in some foods and feeds in varying proportions. However, aflatoxin $B_{1}$ usually predominates and is the most toxic. In the United States, aflatoxins have been identified in corn and corn products, peanuts and peanut products, cottonseed, milk, animal feeds, and tree nuts such as Brazil nuts, pecans, pistachio nuts, and walnuts. Other grains and nuts are susceptible, but are less prone to contamination.

Scombrotoxin (Histamine). Scombroid poisoning or histamine poisoning occurs when foods that contain high levels of histamine (or possibly other vascactive amines and compounds) are ingested. Histamine is produced by the microbial degradation of histidine, a free amino acid found in abundance in dark-fleshed fish, including members of the Scombridae family from temperate and tropical regions. Fish that have been temperature abused are the most commonly implicated foods. Other foods such as Swiss cheese have been reported to cause illness as well. Fish most often implicated are mahi mahi, tuna, mackerel, bluefish, and amberjack.

Ciguatera. Ciguatera is a form of human poisoning caused by the consumption of subtropical and tropical marine finfish which have accumulated naturally occurring toxins through their diet. The toxins originate from several dinoflagellate (algae) species common to ciguatera endemic regions and accumulate through the food chain. Manifestations of ciguatera in humans usually involves a combination of gastrointestinal, neurological, and cardiovascular disorders. 
Marine finfish most commonly implicated in ciguatera fish poisoning are predators and include the groupers, barracudas, snappers, jacks, mackerel, and triggerfish. Other species of warm-water fishes have been reported to harbor ciguatera toxins. The presence of toxic fish is sporadic; not all fish from a given locality or species will be toxic.

Mushroom toxins. Mushroom poisoning is caused by the consumption of raw or cooked fruiting bodies of certain higher fungi. Unlike the previously mentioned aflatoxins, which are secondary metabolites produced when a contaminating mold grows on a food product, the mushroom itself is the toxic food product. Many species of mushrooms are toxic and there is no general rule to distinguish between edible and toxic species. Mushroom poisonings are usually caused by ingestion of toxic wild mushrooms that have been confused with edible species. Most mushrooms that cause human poisoning cannot be rendered nontoxic by cooking, canning, or freezing.

Shellfish toxins. Shellfish poisoning is caused by a group of toxins elaborated by planktonic algae (dinoflagellates, in most cases) upon which the shellfish feed. Under the appropriate conditions toxic dinoflagellate populations may increase to high levels and persist for several weeks. The shellfish may accumulate and metabolize these toxins during their filter feeding. There are four types of shellfish poisonings: paralytic shellfish poisoning (PSP); diarrheic shellfish poisoning (DSP); neurotoxic shellfish poisoning (NSP); and amnesic shellfish poisoning (ASP). Ingestion of contaminated shellfish results in a wide variety of symptoms, depending upon the toxin(s) present, their concentrations in the shellfish, and the amount of contaminated shellfish consumed (Hall 1991). All shellfish (filter-feeding mollusks) could potentially become toxic. However, PSP is generally associated with mussels, clams, cockles, and scallops; NSP with shellfish harvested along the Florida coast and the Gulf of Mexico; DSP with mussels, oysters, and scallops; and ASP with mussels. Control methods include effective monitoring of shellfish lots or growing areas and, in some instances, depuration.

The food processor may control some of these naturally occurring chemical hazards by learning in which foods (i.e., sensitive ingredient) they are most likely to occur. Proper raw material specification, vendor certification, and guarantees along with inspection and spot checks will help to prevent introduction of natural chemical hazards into plant facilities. Likewise, proper handling and storage of sensitive ingredients will prevent conditions conducive to the production of other natural toxicants (e.g., proper storage of grains and feeds to prevent aflatoxin production and avoidance of temperature abuse of fish susceptible to scombroid poisoning). 


\section{Added Chemicals}

The second group of chemicals which may be potential hazards are those that are added to foods at some point between growing, harvesting, processing, storage, and distribution (Table 3-4). These chemicals are generally not considered hazardous if proper conditions of use are followed. Only when these chemicals are misapplied or when their permitted levels are exceeded is there a potential hazard. Cliver (1990) has reviewed the added chemical hazards. The first group of added chemicals includes agricultural chemicals, such as pesticides, herbicides, fungicides, fertilizers, antibiotics, and growth hormones. Pesticides and herbicides are regulated by the Environmental Protection Agency (EPA), which specifically states the permitted uses of each chemical and the maximum allowable residue levels.

Prohibited substances (Table 3-4) are listed in Title 21, Part 189, of the Code of Federal Regulations. Their direct or indirect use in food is prohibited because they present a potential risk to the public health or have not been shown by adequate scientific data to be safe for use in human food.

Toxic elements (e.g., lead, mercury, arsenic) and other toxic compounds (e.g., some chemicals used in the food processing plant) are either not allowed in food at all or have established maximum tolerances. In some cases these chemicals are present naturally and have not been added to the food. Additional reference information on many of these toxic elements can be found in Handbook on the Toxicology of Metals (Friberg, Nordberg and Vouk 1979). Other added chemicals in the food additive group, including direct, secondary direct, and indirect food and color additives, are permitted to be used in actual food processing to preserve the food (e.g., preservatives), enhance flavor, impart color, or nutritionally fortify (e.g., vitamins and minerals). Secondary direct and indirect chemicals used in food processing plants include chemicals such as lubricants, cleaners, sanitizers, paint, and coatings, which may become incorporated into food via migration from packaging materials, or microorganisms and enzyme preparations used in food processing. Allowable limits for all of these food additives have been set in accordance with Good Manufacturing Practices (GMPs). At established limits these chemicals are not hazardous and a large safety factor is incorporated into the regulatory limits; however, if tolerances are exceeded, potential health risks to consumers may occur.

Means of control of chemical hazards are listed in Table 3-5. Foods which contain levels of agricultural chemicals exceeding permitted tolerances should not be accepted. Proper raw material specifications, vendor certification, and guarantees along with inspection and spot checks will help to prevent the introduction or receipt of added chemical hazards in food material. Other chemicals should be checked for intended uses, purity, formulation, and proper labeling. Quantities of chemicals to be added to foods or used in food processing areas 


\section{TABLE 3-5 Control of Chemical Hazards}

I. Control before receipt

Raw material specifications

Vendor certification/guarantees

Spot checks-vertification

II. Control before use

Review purpose for use of chemical

Ensure proper purity, formulation and labeling

Control quantities to be added

III. Control storage and handling conditions

Prevent conditions conducive to production of naturally occurring toxicants

IV. Inventory all chemicals in facility

Review uses

Records of use

must be controlled and recorded. Premeasured quantities of food additives (e.g., preservatives, nitrites, nutritional enhancers, color additives) can be prepared ahead of time and properly labeled or color-coded to avoid confusion in the absence of supervision. Methods to prevent intentionally added chemical hazards are similar to those prescribed for preventing intentionally added physical hazards.

\section{PHYSICAL HAZARDS}

Physical hazards are often described as extraneous matter or foreign objects and include any physical matter not normally found in food which may cause illness (including psychological trauma) or injury to an individual (Corlett 1991). The FDA maintains a passive surveillance system known as the Complaint Reporting System for the reporting of consumer complaints related to food items. A total of 10,923 complaints regarding food items consumed during the period October 1, 1988, through September 30, 1989, were reported to the FDA Complaint Reporting System (Hyman, Klontz and Tollefson 1991). The largest single category $(2,726$ complaints) involved the presence of foreign objects in food and accounted for $25 \%$ of all complaints. Of all reported foreign object complaints, $387(14 \%)$ resulted in illness or injury. The most common foreign object in those reports was glass. Table 3-6 lists the most frequently implicated food types involved in foreign object complaints. One reason physical hazards are the most often reported complaint is that foreign objects provide tangible evidence of a product deficiency. Regulatory action may be initiated when agencies find 
adulterated foods or foods that are manufactured, packed or held under conditions whereby they may have become contaminated or rendered injurious to health. Thus, although the discovery of filth in a product may not itself present an unacceptable heath risk, the conditions of manufacture, packaging, or storage that permitted its entry present an unacceptable health risk. Food processors must therefore be aware of product adulteration by physical substances and address their control in a HACCP program.

The main physical hazards of concern, their sources, and injury potential are listed in Table 3-7. This list is by no means all inclusive; almost anything imaginable can ultimately be introduced into food and present a physical hazard. Other items not mentioned in Table 3-7 include hair, dirt, paint and paint chips, rust, grease, dust, and paper. The sources of physical hazards include raw materials, water, facility grounds, equipment, building materials, and employee personal effects. Physical hazards may be added inadvertently during distribution and storage, or intentionally introduced (sabotage).

Methods involved in controlling physical hazards include raw material specifications and inspections along with vendor certification and guarantees. Various preventive measures are available to find and remove certain physical hazards. Metal detectors can be used to locate ferrous and nonferrous metals in foods; various foreign objects, especially bone fragments can be found through X-ray technology. Effective pest control and foreign object removal from plant environments are also essential. Preventive maintenance and sanitation programs for plants and equipment are necessary. Proper shipping, receiving, distribution and

TABLE 3-6 Eight Most Common Food

Categories Implicated in Reported

Foreign Object Complaints ${ }^{\mathrm{a}}$

\begin{tabular}{lcr}
\hline Food Category & $\begin{array}{c}\text { Number of } \\
\text { Complaints }\end{array}$ & Percent $^{\mathrm{b}}$ \\
\hline Bakery & 277 & 10.2 \\
Soft drinks & 228 & 8.4 \\
Vegetables & 226 & 8.3 \\
Infant foods & 187 & 6.9 \\
Fruits & 183 & 6.7 \\
Cereal & 180 & 6.6 \\
Fishery & 145 & 5.3 \\
Chocolate and & 132 & 4.8 \\
cocoa products & & \\
\hline
\end{tabular}

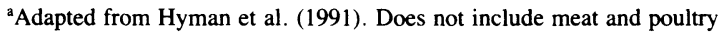
categories or suspected or confirmed tampering complaints.

bPercent of total $(2,726)$ reported foreign object complaints received by the FDA Complaint Reporting System from 10/1/88 through 9/30/89. 


\section{TABLE 3-7 Main Materials of Concern as Physical Hazards and Common Sources $^{\text {a }}$}

\begin{tabular}{|c|c|c|}
\hline Material & Injury Potential & Sources \\
\hline Glass & $\begin{array}{l}\text { Cuts, bleeding; may require surgery } \\
\text { to find or remove }\end{array}$ & $\begin{array}{l}\text { Bottles, jars, light fixtures, } \\
\text { utensils, gauge covers }\end{array}$ \\
\hline Wood & $\begin{array}{l}\text { Cuts, infection, choking; may } \\
\text { require surgery to remove }\end{array}$ & $\begin{array}{l}\text { Fields, pallets, boxes, } \\
\text { buildings }\end{array}$ \\
\hline Stones & Choking, broken teeth & Fields, buildings \\
\hline Metal & $\begin{array}{l}\text { Cuts, infection; may require } \\
\text { surgery to remove }\end{array}$ & $\begin{array}{l}\text { Machinery, fields, wire, } \\
\text { employees }\end{array}$ \\
\hline $\begin{array}{l}\text { Insects and } \\
\text { other filth }\end{array}$ & Illness, trauma, choking & $\begin{array}{l}\text { Fields, plant post-process } \\
\text { entry }\end{array}$ \\
\hline Insulation & Choking; long-term if asbestos & Building materials \\
\hline Bone & Choking, trauma & $\begin{array}{l}\text { Fields, improper plant } \\
\text { processing }\end{array}$ \\
\hline Plastic & $\begin{array}{l}\text { Choking, cuts, infection; may } \\
\text { require surgery to remove }\end{array}$ & $\begin{array}{l}\text { Fields, plant packaging } \\
\text { materials, pallets, } \\
\text { employees }\end{array}$ \\
\hline $\begin{array}{r}\text { Personal } \\
\text { effects }\end{array}$ & $\begin{array}{l}\text { Choking, cuts, broken teeth; may } \\
\text { require surgery to remove }\end{array}$ & Employees \\
\hline
\end{tabular}

${ }^{\mathrm{a}}$ Adapted from Corlett (1991).

storage procedures as well as packaging material handling practices (particularly those involving glass) must be evaluated for their potential to introduce hazards. Packaging should be tamper-proof and at least tamper-evident. Finally, employee education and practices must involve knowledge and prevention of physical hazard introduction.

\section{ACKNOWLEDGMENTS}

The author thanks the many FDA scientists who contributed to the internal FDA document Foodborne Pathogenic Microorganisms and Natural Toxins, from which much of the information in this chapter was obtained.

\section{References}

Archer, D.L. and Kvenberg, J.E. 1985. Incidence and cost of foodborne diarrheal disease in the United States. J. Food Prot. 48: 887-894.

Bryan, F.L. 1979. Epidemiology of foodborne diseases. In Food-Borne Infections and Intoxications. (Ed.) H. Riemann and F.L. Bryan, p. 4-69. Academic Press, New York. Bryan, F.L. 1984. Appendix: Diseases transmitted by foods. In Adverse Reactions to Foods. (Ed.) J.A. Anderson and D.D. Sogn, p. 1-101. U.S. Dept. of Health and Human Services, NIH Publication No. 84-2442, Washington, DC. Cheng, T.C. 1986. General Parasitology. Academic Press, Orlando. 
Cliver, D.O. 1988. Virus transmission via foods; A scientific status summary by the Institute of Food Technologists' Expert Panel on Food Safety and Nutrition. Food Technol. 42(10): 241-248.

Cliver, D.O. 1990. Foodborne Diseases. Academic Press, San Diego, CA.

Corlett, D.A. 1991. A practical approach to HACPP. Food Safety Management Seminar. ESCAgenetics Corp., 830 Bransten Rd., San Carlos, CA.

Doyle, M.P. (Ed.). 1989. Foodborne Bacterial Pathogens. Marcel Dekker, Inc., New York.

Friberg, L., Nordberg, G. F., and Vouk, V. B. 1979. Handbook on the Toxicology of Metals. Elsevier/North-Holland, Amsterdam.

Hall, S. 1991. Natural Toxins. In Microbiology of Marine Food Products. (Ed.) D. Ward and C. Hackney, p. 301-330. Van Nostrand Reinhold, New York.

Healy, G.R., Jackson, G.J., Lichtenfels, J.R., Hoffman, G.L., and Cheng, T.C. 1984. Foodborne parasites. In Compendium of Methods for the Microbiological Examination of Foods. (Ed.) M.L. Speck, p. 542-556. American Public Health Assoc., Washington, DC.

Hyman, F.N., Klontz, K.C., and Tollefson, L. 1991. The role of foreign objects in the cause of foodborne injuries: Surveillance by the Food \& Drug Administration. (Submitted for publication.)

International Commission on Microbiological Specifications for Foods. (ICMSF). 1986. Microorganisms in Foods. Vol. 2. Univ. of Toronto Press, Toronto.

Jackson, G.L. 1990. Parasitic protozoa and worms relevant to the U.S. Food Technol. 44(5): 106-1112.

Riemann, H. and Bryan, F.L. 1979. Foodborne Infections and Intoxications. Academic Press, New York.

Shapton, D.A. and Shapton, N.F. Principles and Practices for the Safe Processing of Foods. Butterworth-Heinemann Ltd., Oxford.

Stoloff, L. 1984. Toxigenic fungi. In Compendium of Methods for the Microbiological Examination of Foods. (Ed.) M.L. Speck, p. 557-572. American Public Health Assoc., Washington, DC.

Todd, E.C.D. 1989. Preliminary estimates of costs of foodborne disease in the United States. J. Food Prot. 52: 595-601.

Ward, D. and Hackney, C. 1991. Microbiology of Marine Food Products. Van Nostrand Reinhold, New York. 